\title{
Dimension of climate variability in the socio-economic sectors in Niger
}

\author{
Ali Nouhou \\ Department of Geography, FLSH, Abdou Moumouni University, Niamey, Niger \\ DOI: 10.29322/IJSRP.10.11.2020.p10738 \\ http://dx.doi.org/10.29322/IJSRP.10.11.2020.p10738
}

\begin{abstract}
The objective of this study is to analyze the dimension of climate variability in the main socio-economic sectors in Niger (agriculture, livestock, transport, health). The climatic situation since 1992 is characterized by a sudden alternation between very wet and very dry years, rather than an alternation of wet (1950-19698) or dry periods (1970-1991). The number of people affected has been steadily increasing, rising from 24,234 in 2013 to more than 430,000 in 2020. The damaged crop areas have increased fivefold while the number of decimated livestock has increased eightfold between 2012 and 2018. Transport infrastructure, particularly bridges, most of which were built in the 1970s and 1990s, i.e. during the periods of rainfall deficits, no longer respond to current climatic conditions (intense rainfall, increasing gullying, reactivation of dead valleys, rising water tables, etc.).
\end{abstract}

Keywords: Climate variability, Droughts, Floods, Republic of Niger.

\section{Introduction}

Africa in general, and the Sahel in particular, are among the areas most exposed to the effects of climate change. Floods, droughts, deforestation (Arthur et al. 2006, Jubek et al. 2019) and the drying up of lake areas and their impacts on the lives of millions of people are just a few examples of the impact of climate change on human lives and activities.

Niger has a Sahelian-type climate characterized by high interannual variability in rainfall resulting in increasingly frequent dry and wet years. This situation is linked to the nature of the climate and climate change, whose extreme adverse events are hampering the country's development. Indeed, since the major droughts of the 1970s and 1980s, Niger has faced an accelerated degradation of its environment. That degradation has caused not only the reduction and decline of the productive potential of the "natural resource capital", but also the disarticulation of the centuries-old systems of production and management of natural environments. The fragility of the country's ecosystems makes it very vulnerable to these phenomena, not to mention the fact that the difficult socio-economic context also weakens the adaptive capacities of the populations. In addition, the population census of 2012 indicates a rapid increase in population (22 752385 hbts in 2020) with a growth rate of 3.9\% per year.

In the Sahel, a highly vulnerable ecological environment, the climate has a significant influence on the socio-economic sectors such as agriculture, livestock, transport and health. In Niger, more than $80 \%$ of the agro-pastoral activities are carried out between the $100 \mathrm{~mm}$ and $500 \mathrm{~mm}$ isohyets, i.e. between the Saharo-Sahelian bands. 


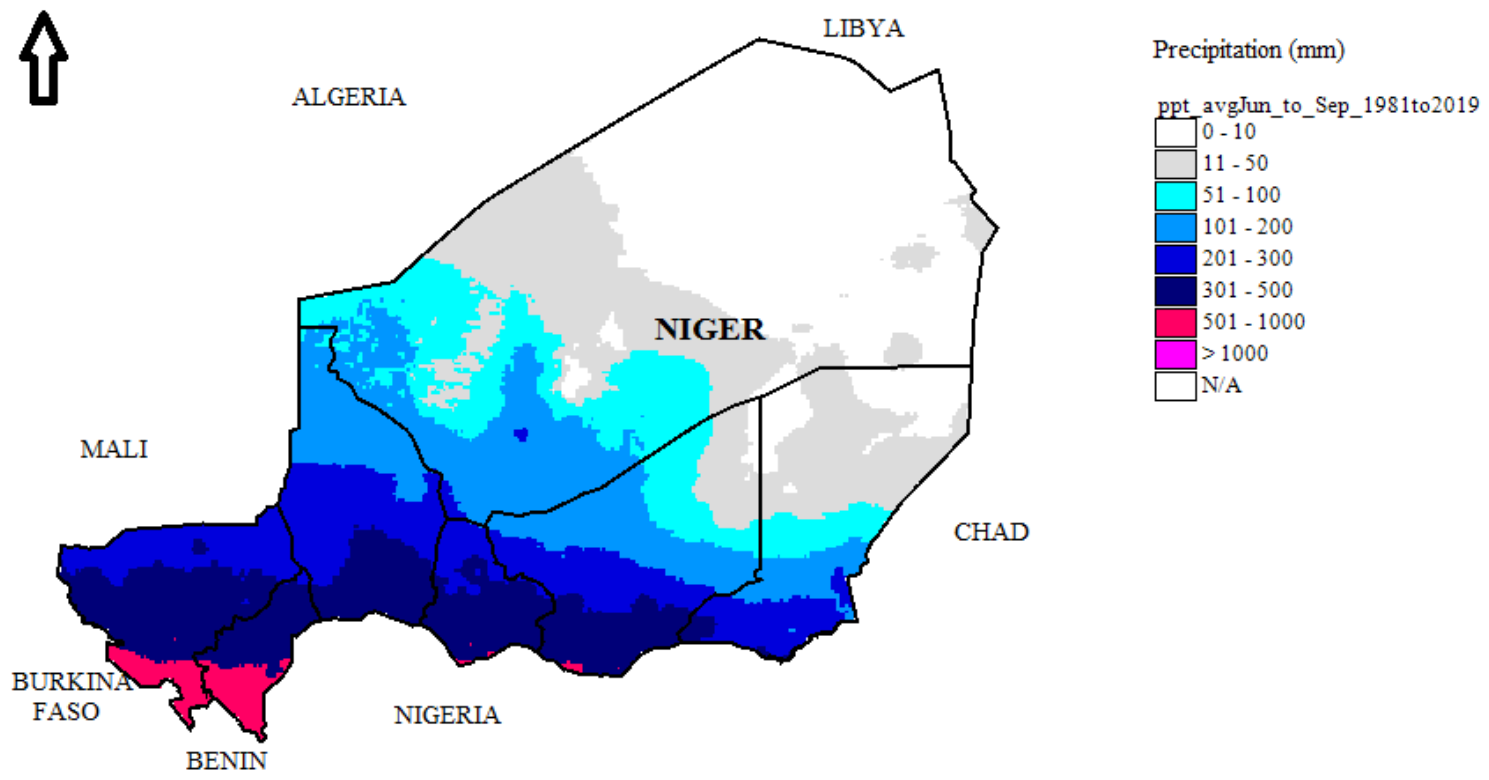

Fig. 1: Rainfall map of Niger (1981-2019)

Data source: GEOCLIM 2020

The soils of its environments are very sensitive to erosions (wind, water and chemical). Rain and river floods are also common, especially along the Niger River bed, valleys and ponds. We can remember the floods in Niamey in 2012, 2020 and those of the Goulbi in Maradi in July 2020. The agropastoral vulnerability of the climate is exacerbated by traditional practices, poverty or even the passivity of farmers and inefficient development plans.

The health and transport systems are developing, but they depend highly on external or private support. In the face of these inadequacies of the means of intervention and the quality of service, the country is continually affected by climatic phenomena (flooding, climate-sensitive diseases, and drought).

The transport infrastructure, particularly bridges, most of which were built between 1970 and 1990, i.e., during the periods of rainfall deficits, no longer meet current conditions (intense rainfall, increasing gullying, reactivation of dead valleys, rising water tables, etc.).

\section{Methodology}

Data sources

This study is based, on the one hand, on an analysis of statistical data and, on the other hand, on an analysis of documentary data from the relevant services (CNEDD, INRAN, and AGHRYMET) and the Ministries concerned (agriculture, environment, livestock, transport, hydraulics, health). They concern the elements of the climate, including temperatures and rainfall as well as sectoral production. Data and assessments of major floods and droughts are analyzed.

Materials

These are:

- data extraction and processing software: GeoCLIM, Excel;

- Field equipment including:

- one (01) Garmin GPS for the recording of geographic coordinates;

- one (01) digital camera for taking photos in the field.

\section{Results}

It is important to first clarify the nuance between the terms climate "change" and "variability". Variability refers to natural fluctuations in climate, including average states and extreme events. Climate is naturally in constant evolution. Climate change occurs when standard variations (patterns of climate variability and mean values) undergo significant measurable changes over the long term.

In the glossary of the IPCC (Intergovernmental Panel on Climate Change, 2013), the United Nations Framework Convention on Climate Change (UNFCCC) defines climate change as "changes that are attributed directly or indirectly to human activity that alters the composition of the global atmosphere and that are additional to natural climate variability observed over comparable time periods". The UNFCCC thus distinguishes between climate change due to human activities altering the composition of the atmosphere and climate variability due to natural causes. 
The rainfall evolution in the Sahel is characterized by two distinct periods:

- the period 1950 - 1969 which was marked by a succession of wet years and the period 1970 - 1991 by a persistence of dry years. The end or not of the drought in the Sahel is currently the subject of debate within the scientific community. Some analyses conclude on the end of the phenomenon while others insist on its continuity.

- The situation from 1970 to 1991: To determine the wet or dry character of the rainy season, the standardized rainfall index (SPI) is commonly used. For a given year, this index averages the seasonal rainfall totals of the available rainfall stations. Thus, the SPI indicates whether the season can be described as surplus (if positive) or deficit (if negative).

Analysis of the Sahelian SPI, calculated on the basis of data from 600 stations monitored by the AGRHYMET Regional Center (2010), highlights two distinct periods (Fig., blue and pink parts). The first, from 1950 to 1969, is characterized by a persistence of wet years and the second, from 1970 to 1991, by a persistence of more than twenty dry years. The 1970s thus mark what is commonly called the climatic rupture in the Sahel. Such rainfall behavior has not been observed in any other region of the world. This analysis constitutes a consensus within the scientific community. Numerous international programs have studied the rainfall in the region in an attempt to explain the phenomenon, the latest and most ambitious being the AMMA program (Multidisciplinary Analysis of the African Monsoon). The drought observed in the Sahel during the period 1970-1991 also had no equivalent in its spatial dimension: it affected the entire region without exception.

The situation from 1992 onwards is characterized by a brutal alternation between very wet and very dry years, rather than a dry or wet period, an allusion to the situation before. Inter-annual variability has increased with the new mode of variability, making interannual rainfall forecasting in the Sahel even more difficult.

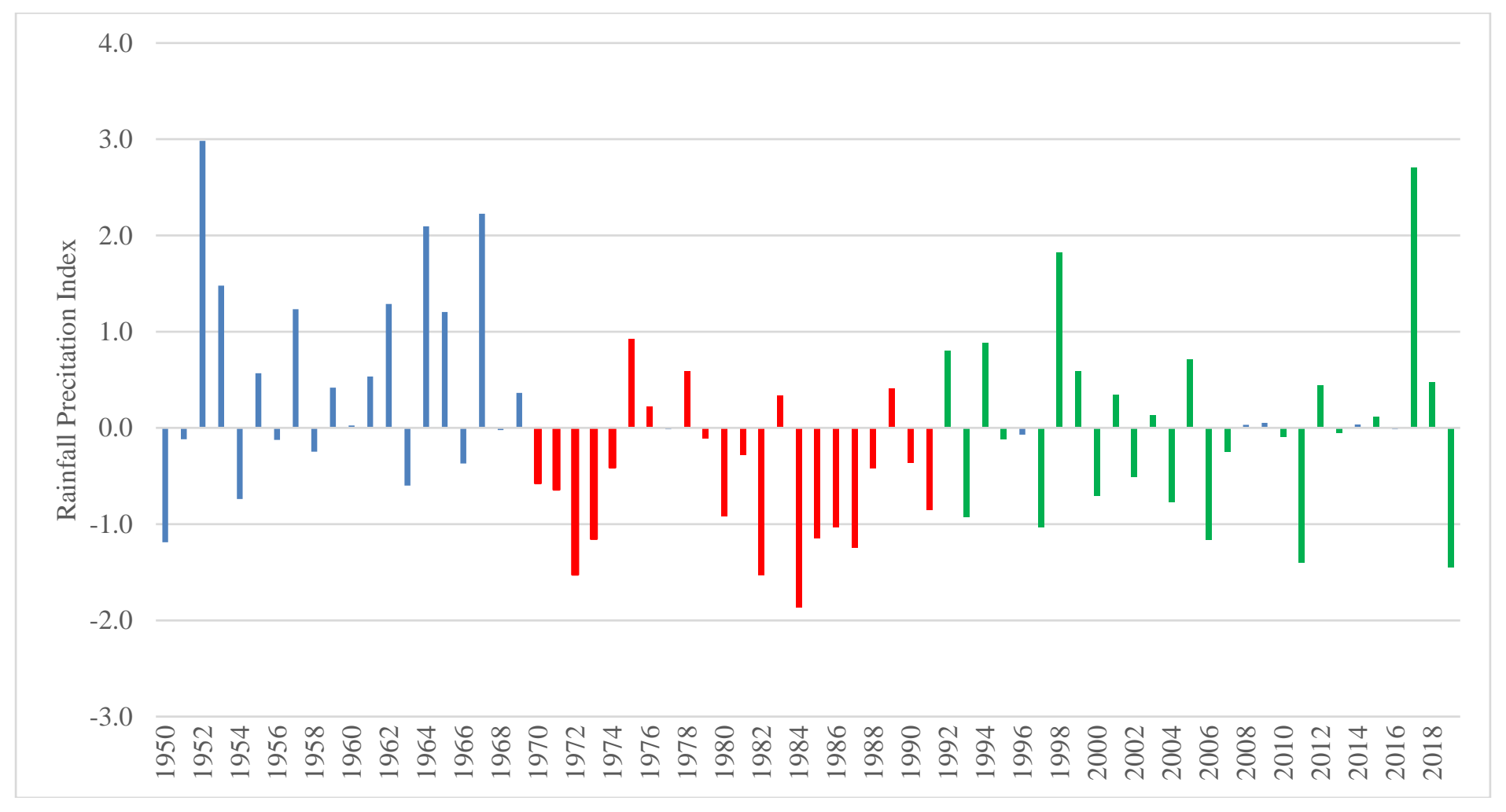

Fig. 2: Rainfall Index (RPI) of the Sahel over the period 1950-2019

Source: Climatic data Agrhymet 2019.

Positive values indicate years of above-average rainfall over the period 1950-2019 and negative values indicate years of belowaverage rainfall.

In 2012, Agadez, a city in the far north, has the heaviest toll with 60,555 victims, deplores the UN agency. Last week the authorities of Agadez said that the bad weather had already caused 16 deaths, including 7 in the city of Agadez alone, classified by UNESCO as a World Heritage Site.

Among the other hard hit regions are Maradi (center-south) with 34,877 victims, Zinder (center-east) with 13,601 victims and Diffa (south-east, very arid) with 10,992 victims, according to the UN report.

In 2017, the heaviest toll was recorded in the capital with 21 dead and 10 injured, in Maradi (9 dead and 26 injured) and in Tillabéri and Zinder (8 dead each). In Agadez (north), at the gates of the desert, there were 19,726 victims.

This publication is licensed under Creative Commons Attribution CC BY.

http://dx.doi.org/10.29322/IJSRP.10.11.2020.p10738

www.ijsrp.org 
According to Ocha, 9,267 houses and 31 schools collapsed and 16,048 head of cattle perished throughout the country. In addition, 709 wells were buried and more than 84 tons of grain and 9,804 hectares of fields and gardens were destroyed, again according to the UN agency.

In 2018, the regions "most impacted" by the bad weather are Maradi (center-south), Diffa (south-east), Zinder (center-east), Tahoua (west). Some 2,000-homeless people have been identified in the capital, Niamey.

In 2020, it is mostly the capital Niamey, especially the right bank of the river, which was affected by floods making more than 49,000 victims. In the region of Maradi, there were a total of 136000 victims (OCHA 2020).

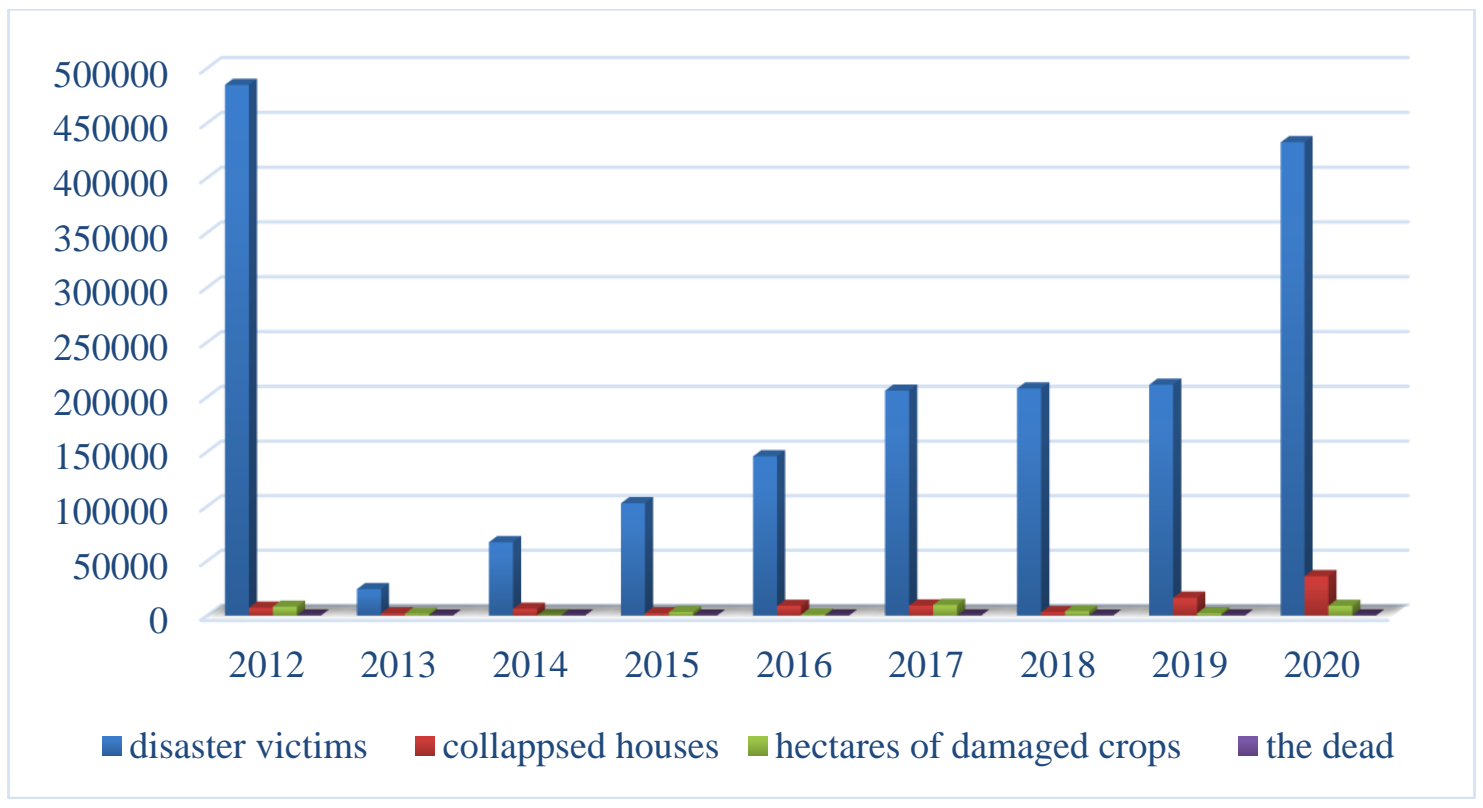

Fig. 3: Summary assessment of the floods in Niger (2012-2020)

Source: statistics of OCHA

In sum, the number of people affected is constantly increasing from 24, 234 in 2013 to more than 430, 000 in 2020 (OCHA 2020). The area of the damaged crops has increased fivefold while the number of decimated livestock increased eightfold between $2012(3,118)$ and $2018(2,6344)$.

\subsection{Agriculture and climate variability}

Agriculture in Niger is essentially rainfed and dominated by cereals (millet, sorghum, maize, rice) and cash crops (cowpea, groundnut, voandzou, sesame, sorrel, souchet, cotton). Under irrigation, Niger also produces rice in hydro-agricultural developments and vegetable crops, mainly onions. The potential for arable land is estimated at 15 million hectares, of which only 270,000 hectares are irrigable.

Climate variability affects all dimensions of food security for vulnerable groups (Alessandra et al. 2016, Alexis et al. 2017). According to the definition adopted at the World Food Summit in Rome in 1996: Food security exists when all people, at all times, have physical and economic access to sufficient, safe and nutritious food to meet their dietary needs and food preferences for an active and healthy life.

$85 \%$ of Niger's cultivable soils are dune, not very productive, fragile and very sensitive to water and wind erosion. Peasant farming practices are characterized by a low level of intensification and remain largely manual. Yields are low and highly fluctuating. The low level of fertilization, the reduction of fallow land and the extension of cropland by clearing marginal land encourage the development of water and wind erosion and no longer ensure the reproduction of soil fertility.

Agriculture is essentially rainfed and therefore based on the rainfall regime of the country. On the basis of rainfall, four agro-climatic zones can be distinguished:

- the Sahelo-Sudanian zone, which represents about $1 \%$ of the total area of the country and receives 600 to $800 \mathrm{~mm}$ of rain per year in normal years ;

- the Sahelian zone covers $10 \%$ of the country and receives 500 to $600 \mathrm{~mm}$ of rainfall;

- the Sahelo-Saharan zone which represents $12 \%$ of the country's surface area (150 to $350 \mathrm{~mm} / \mathrm{year}$ );

- the Saharan desert zone, which covers $77 \%$ of the country (less than $150 \mathrm{~mm} /$ year) (CNEDD, 2011). 
Yields are constantly decreasing substantially due to deteriorating weather conditions. Over the last 20 years, a decline of around $30 \%$ has been observed, reflecting the decline in soil fertility, one of the major problems of agriculture in Niger (CNEDD, 2011). This situation is at the root of the production deficit recorded almost one year out of three (between 200,000 and 300,000 tons), thus causing a decrease in food self-sufficiency and forcing significant food imports.

From the 1970s to 2011, it was mainly droughts that caused major crop or yield losses. Niger experiences regular droughts (Alpha 1993, CNEDD 2011), causing serious famines that recur every ten years like those of:

- 1855: great spontaneous famine caused by droughts

- 1870 great famine caused by droughts

- 1900-1901: Great famine caused by droughts that led to an unprecedented exodus of rural people to large cities and coastal countries;

- 1910 to 1917 with rainfall deficits of 135 to $377 \mathrm{~mm}$ leading to a total absence of grain in the markets;

- 1923-1924 having mainly affected livestock with generalized fodder deficits;

- 1930-1931: Exceptional drought and locust invasion;

- 1944: famine in northwestern Niger due to a rainfall deficit;

- 1966-1967 famine that gave the name of Bandabari to a district of Niamey created spontaneously by the populations of the affected regions who found refuge in the capital.

- $\quad 1972-1975$ with a drastic drop in food production which reached 400,000 tons in 1973;

- 1983-1985, with the great drought following the deterioration of climatic conditions;

- $\quad$ 1990-1994, during which food difficulties were recorded;

- 1996-1997, having recorded a rainfall deficit;

- 2001, Niger experienced a particularly acute food crisis in several regions;

- 2004-2005, the food crisis was linked mainly to the locust invasion, cereal deficits, and difficulties in accessing markets for the poorest people. A total of 3,500,000 people were food insecure ( $29 \%$ of the country's total population);

- 2008, about 30\% of the Nigerien population was food insecure, including 9\% in severe insecurity. In other words, nearly 6 out of 10 agricultural households could not cover their food needs for more than three months out of twelve and more than $20 \%$ of households had a qualitatively poor diet;

- 2010 , following a cereal deficit related to a poor distribution of rainfall in time and space during the 2009 rainy season;

- 2011 another food crisis affects 7.1 million people, or $48 \%$ of the population. That new crisis confirms a structural problem related to the insufficient implementation of agricultural policies, or even their inadequacy (Yayé et al. 2010, Ministry of Agriculture 2017).

It should be noted that since 2012, there are more and more agricultural losses caused by floods.

The impact of climate variability on agriculture is not only reflected in reduced yields. In addition to climatic manifestations (irregular distribution in time and space of low rainfall, sometimes heavy rains causing flooding or land erosion, and manifestations of high temperatures that lead to scalding of ears before maturation), this impact is also manifested by a transformation of cropping systems (Lona, 2011) resulting in :

$\checkmark$ the modification of the entire agricultural calendar: soil preparation is neglected because the urgency is now given to sowing; crop establishment tends to take place at the same time for millet, sorghum and cowpea as soon as the first rains come, whereas cowpea is usually sown after the first weeding of millet.

$\checkmark \quad$ Weeding is less numerous and faster (weed pressure is lower) due to the shortening of the rainy season;

$\checkmark$ the abandonment of traditional rice cultivation due to the insufficient flooding of the river, aggravating the food insecurity of the population;

$\checkmark$ the drastic reduction of the areas allocated to flooded rice in favor of rice in individual pumping systems and hydroagricultural developments,

$\checkmark$ the abandonment of groundnut cultivation because of the importance given by farmers to cereals since the various food crises that have followed one another;

$\checkmark$ the abandonment of cotton grown particularly along the riverbank in favor of rice and tobacco cultivation since the Bandabari famine (1966) and the 1973 drought;

$\checkmark$ the abandonment of flood recession sorghum cultivation following the low floods and severe low water levels recorded since the early 1970s and the late millet variety Somno,

$\checkmark$ The extension of the sorghum cultivated areas: Sorghum that was cultivated around the river (flood recession sorghum) has experienced a considerable rise towards the plateaus. Thus, with the advent of other varieties, the crop first gained ground in the lowlands (edges of ponds and marigots, etc.), then in the glacis with the advent of the plough, and now even on dune soils;

$\checkmark$ the extension of the cultivation of cucurbits (Cucurbita maxima, Citrullus lanatus and Lagenaria siceraria): this crop, which was specific to the river area, is nowadays found in the bed of dry ponds,

$\checkmark$ the generalization of the cowpea cultivation, drought resistant and fodder plant ;

$\checkmark$ the fragmentation of family land holdings due to demographic pressure; 
$\checkmark$ the reduction or even disappearance of fallow land, which indicates a land blockage at the household and land levels and poses the problem of soil fertility management;

$\checkmark$ the increase in the frequency of poor harvests: The phenomenon has even become chronic in recent years to such an extent that some farmers say: "there are only deficit years in their land".

$\checkmark$ the modification of the location of optimal growing areas due to the shift in isohyets: the case of the modification of West African cotton growing areas, with the disappearance of the cotton zone in Niger.

Recent studies have already shown that yields of crops such as millet/sorghum will decrease by more than $10 \%$ in the case of a temperature increase of $+2^{\circ} \mathrm{C}$ and insignificant variations in rainfall by 2050. An increase of $+3^{\circ} \mathrm{C}$ will lead to a decrease in agricultural yields of about 15 to $25 \%$. (Sarr et al. 2007; AGRHYMET, 2009).

\subsection{Livestock and climate variability}

This section looks at the consequences of climate change on the size of the livestock in Niger on the one hand, and the fodder balance sheet on the other. With a livestock estimated at nearly 41 million heads or 15,829,818 TBU in 2014 all species combined and for a total value of more than 3,000 billion CFA francs, Niger is a breeding country par excellence (Ministry of Agriculture 2017). Livestock farming is credited with a $15 \%$ contribution to the national GDP and contributes $42.29 \%$ to the formation of the agricultural GDP. The livestock sub-sector also constitutes the country's second largest export revenue (23.7\% of the total value of exports) after uranium (62.76\%). With respect to food security and the fight against poverty, the contribution of livestock farming is on average $15 \%$ of household income and 25\% to meeting food needs. (Ministry of Agriculture 2017).

Apart from droughts, as was the case for agriculture, floods mainly impact herds in depressions, on the edges of valleys and ponds. Livestock farming is therefore confronted with climatic variability for which it is called upon to suffer the consequences (see following figures).

Table 1: Animal losses caused by climatic hazards (drought and floods)

\begin{tabular}{|l|l|l|l|l|l|}
\hline Period & Causes & Cattle & Sheep & Goats & Dromedaries \\
\hline $1973-1974$ & $\begin{array}{l}\text { Generalized } \\
\text { drought }\end{array}$ & $45 \%$ & $27 \%$ & $15 \%$ & - \\
\hline $1984-1985$ & $\begin{array}{l}\text { Generalized } \\
\text { drought }\end{array}$ & $40 \%$ & $35 \%$ & $33 \%$ & - \\
\hline $2004-2005$ & $\begin{array}{l}\text { Drought and } \\
\text { acridian invasions }\end{array}$ & $20 \%$ & $16 \%$ & $13 \%$ & - \\
\hline $2009-2010$ & $\begin{array}{l}\text { Drought and } \\
\text { acridian invasions }\end{array}$ & $25,5 \%$ & $38,6 \%$ & $31,3 \%$ & $2,6 \%$ \\
\hline
\end{tabular}

Source: Ministry of Agriculture 2017

Table 2: death rate per flood/ heavy rain in accordance with species and counties

\begin{tabular}{|l|l|l|l|l|l|l|}
\hline \multicolumn{1}{|c|}{ species } & cattle & sheep & goats & camels & horses/donkeys & total \\
\hline Tchirozérine & 28060 & 115189 & 13546 & 46 & 7008 & 163849 \\
\hline Mainé-Soroa & 1153 & 1821 & 1354 & 0 & 20 & 4348 \\
\hline Dogondoutchi & 4004 & 6635 & 5847 & 0 & 2 & 16488 \\
\hline Dakoro & 6048 & 27569 & 0 & 34 & 1500 & 35151 \\
\hline Abalak & 6756 & 11898 & 11815 & 37 & 898 & 31404 \\
\hline Tchintabaraden & 1213 & 5208 & 0 & 107 & 325 & 6853 \\
\hline Tillabéri & 5800 & 6450 & 13600 & 210 & 635 & 26695 \\
\hline Filingué & 1156 & 1520 & 1076 & 0 & 0 & 3752 \\
\hline Ouallam & 558 & 8173 & 570 & 38 & 171 & 9510 \\
\hline Téra & 22 & 173 & 139 & 0 & 0 & 334 \\
\hline Gouré & 9999 & 25859 & 1316 & 273 & 336 & 37783 \\
\hline Tanout & 947 & 5614 & 230 & 7 & 371 & 7169 \\
\hline Total & 65716 & 216109 & 49493 & 752 & 11266 & 343336 \\
\hline
\end{tabular}

Source: Ministry of Agriculture 2017

This publication is licensed under Creative Commons Attribution CC BY. 
From 1973 to 2020, Niger experienced enormous livestock losses due to droughts and floods. As for the fodder deficit, it led to the loss of 2,725,427 head of livestock of all species, or $13.51 \%$ of the total livestock population of the regions concerned (Ministry of Agriculture 2017).

The loss of herds caught by runoff in depressions, valleys and around ponds. For example, in Kongou, a village located 10 Kongou Northeast of Niamey, the valley took 275 head of cattle, a loss due to the overflow of the valley after the heavy rains of the first week of September 2020.

\subsection{Transportation and Climate Variability}

The impacts of climate variability on road infrastructure are generally due to extreme conditions (heavy rains, river overflows, high winds and high temperatures). These conditions have an impact on the various factors during the operation of a road or engineering structure. Most of these factors have a direct or indirect impact on society, the economy, safety (driver, vehicle), traffic and accessibility:

- safety: these weather conditions have a negative impact on safety because they influence the risk of accidents. For example a road can be cut by a flood (RN 1 in Binin' Gaouré August 2020), rain and wind reduce visibility, grip and control of the vehicle. Extreme temperatures increase the temperature of the roadway which leads to the bursting of the wheels and decreases the comfort of passengers ;

- traffic: Road users tend to adapt their speed to outside conditions, resulting in lower speeds. Traffic can also be influenced by road conditions, as a very marked deterioration of the road infrastructure slows down, prevents and impedes traffic. Large carriers take time to deliver goods, which impacts the trade circuit, thus the economy and causes loss of life and property;

- Accessibility: weather conditions lead to a decrease in the accessibility of a network and the surrounding regions.

In the region of Agadez, the cuts, on the axis of the RN1 ZINDER-AGADEZ-ARLIT PK 379 (50km from Agadez), are due to the displacement of sand dunes which are mainly caused by strong winds raising dust and sand. These hot and dry winds blow in March and April and the intervention is done every 48 hours after their passage which can last more than a week. The increase in rainfall due to climate variability and change observed during the last decade throughout the country has led to the reactivation and silting of all the ancient koris, particularly in the region of Agadez and poses traffic difficulties. In addition, the structures in that region are subject to high temperatures during the day and low temperatures at night. These extreme temperature variations lead to abrasion and cracking of the materials of the structures (crumbling of the concrete of the structures, volatility of the tar, degrades their resistance and shortens their lifespan).

In the region of Diffa too, it is the silting due to strong winds and extreme temperatures that cause road cuts and damage to the structures. In 2016, the regional directorate of equipment of Diffa carried out twenty (28) road de-silting operations that total 8004 $\mathrm{m} 3$ of sand cleared, equivalent to 667 trucks of $12 \mathrm{~m} 3$ (Republique du Niger 2017).

In September 2018, at the Benin-Niger border (Malanville) after the collapse of a bridge, 732 trucks were immobilized. Detours to Nigeria and Burkina Faso were necessary to establish road traffic, especially goods traffic to Niger. Some passengers used canoes at the collapsed bridge.

There are a multitude of bridges such as the one at Bangawi $40 \mathrm{~km}$ west of Niamey on the National Road $\mathrm{N}^{\circ} 1$ whose pillars gave way following heavy rains and that information is only known by the people who use these roads. At the eastern exit of Niamey (Route Filingué), the tar passing over a lowland was impassable for three weeks. Each year of excess rainfall brings a destruction of the roads, especially the bridges.

\subsection{Health and climate variability}

In Niger, the impacts of climate variability on health mainly concern climate-sensitive diseases such as malaria, meningitis and measles. Indeed, droughts, combined with high temperatures, accentuates the spread of certain diseases such as meningitis (Garcia et al. 2014; Prudence et al. 2019), while heavy rains and floods promote the proliferation of certain endemic diseases, the most dangerous of which is malaria.

Sand and/or dust storms, combined with the extremes of certain climatic variables such as temperature and relative humidity, considerably accentuate certain respiratory diseases and cause eye irritation. They may also be associated with the spread of meningitis.

On the nutritional level, a drought results in localized food shortages and famine, which are certainly the causes of malnutrition and fragility of certain vulnerable groups, namely pregnant and nursing women and children.

Meningococcal meningitis is found throughout the world, but it is in the meningitis belt, which extends in sub-Saharan Africa from Senegal in the west to Ethiopia in the east, that the burden of the disease is the highest. Tens of thousands of cases are still reported each year in that area (Ayansina et al. 2020), the true numbers are never known because in rural areas, most patients do not attend medical centers.

During the dry season, between December and June, dust-laden winds and upper respiratory tract infections combine to damage the nasopharyngeal mucosa, increasing the risk of meningococcal disease. 
Meningitis, which used to occure from April onwards due to the high temperatures, now appears even in October, January, February and March because of the climatic variability, the daily maxima due to the Harmattan (hot and dry trade winds) are around $40 \mathrm{C}^{\circ}$ in those months. In 2015, between January and June there were 573 deaths out of a total of 8500 cases.

Meningococcal meningitis appears even in October as soon as temperatures reach 40 degrees as it was the case in 2017 . That is mainly due to too short rainy seasons with rainfall stopping before September 30 or very low rainfall in October not exceeding 5 $\mathrm{mm}$. In many clinics, especially private ones, meningitis during its first days of occurrence is treated like malaria because some of its symptoms (fever) resemble it.

\section{Discussion - Conclusion}

All the regions of Niger are affected by flooding following heavy rains, especially those of 2020 .

On the agricultural level, it is to be retained:

* a change in the location of farming areas;

* a decrease in agricultural yields;

* a change in the types of pests and diseases;

* a food deficit leading to famine or permanent food insecurity;

* a rural exodus leading to the creation in urban areas of communities exposed to delinquency, prostitution, begging, theft and banditry;

* a decrease in the contribution of agriculture to the GDP.

In short, for the livestock sector we retain:

* the decline in rural incomes;

* the profound changes in the composition of herds through a gradual replacement of cattle by small ruminants;

* the malnutrition of the animal population;

* the conversion of a large number of nomadic breeders to sedentary ones;

* the imbalance in the balance of trade, thus a reduction in the contribution of livestock to GDP.

The aid and relief to the disaster victims is summarized in food and health assistance (cereals, soap, oil, mosquito nets).

Each rainy season brings its corollaries (floods, drought, locust and granivorous bird invasion, phytosanitary damage, etc.). Other impacts (damaged road infrastructure, buried wells, tons of cereals washed away, destroyed gardens) remain invaluable most years.

In the future, the roads and bridges of the fossil valleys will be very exposed as flooding (Armel et al 2013), heavy rains and gullying will intensify (Inoussa et al. 2019, Francesco et: al 2020, Augustin et al. 2020). Funds for emergency response and adaptation/mitigation plans are based more on assistance (waiting for external aid) than on the state's own means. That is demonstrated every time there is a disaster such as the floods of September 2020 for which a mobilization meeting is calling for $97.3 \%$ of the 372 billion CFA (US\$660 million) from partners. The disaster victims are always rehoused in schools during the first weeks of the disasters.

Among these activities is the development and dissemination to decision-makers of new products and tools to improve the practice of climate-smart agriculture (CSA). CSA is an approach that identifies the actions needed to transform and reorient agricultural systems to support sustainable development and ensure food security in the context of a changing climate (FAO, 2010). It helps to ensure food security, achieve climate change adaptation and mitigation goals, and reduce poverty.

\section{REFERENCES}

- AGRHYMET. 2009. Actes de l'atelier de restitution des résultats du projet «Appui aux Capacités d'Adaptation du Sahel aux Changements Climatiques». Ouagadougou, 2-4 Février 2009.

- AGRHYMET. 2010. Le Sahel face aux changements climatiques Enjeux pour un développement durable. Niamey, Niger

- Alpha G. B. 1993. Une histoire des famines au Sahel. Étude des grandes crises alimentaires (XIXème - XXème siècles), L'Harmattan, 201 p.

- Alessandra G, Krishna K.P, Rémi C, Naouar L, Richard J. C. 2016. Climate risk and food security in Mali: A historical perspective

on adaptation. Earth's Future, 10.1002/2016EF000404.

- Alexis B, Benjamin R. L, Kirsten F, Alessandra G. 2017. Uncertain soil moisture feedbacks in model projections of Sahel precipitation. Geophysical Research Letters, 10.1002/2017GL073851.

- Armel T. K, Niall P. H, Lara P. 2013. Characterization of the spatial and temporal variability of surface water in the Soudan-Sahel region of Africa. Journal of Geophysical Research: Biogeosciences, Vol. 118, 1472 - 1483.

- Arthur M. G, Alessandra G and Stephen E. Z. 2009. Geophysical Research Letters, Vol. 36, L12701.

- Augustin V and Wassila M. T. 2006. On the forecast of cumulative precipitation at subseasonal time-scales over the Sahel. Geophysical Research Letters, Vol. 33, L14703.

- Ayansina A, Consolato S, Oluwatoyin S. A. 2020. Malaria and meningitis under climate change: initial assessment of climate information service in Nigeria. Meteorol Appl. 2020;27:e1953.

- CNEDD. 2011. Impact des changements climatiques dans le secteur de l'agriculture au Niger. Rapport final, Cabinet du Premier Ministre, Niamey, Niger, 58 p.

- Francesco S.R. P, Marco G, Gabriele M, Alexis B, Danielle M.S, Rowan F. S and Peter B. M. 2020. The Greening of the Sahara:

Past Changes and Future Implications. One Earth 2 , March 20, 2020, 235-250.

This publication is licensed under Creative Commons Attribution CC BY.

http://dx.doi.org/10.29322/IJSRP.10.11.2020.p10738

WwW.ijsrp.org 
- García-Pando C.P, Stanton M.C, Diggle P.J, Trzaska S, Miller R.L, Perlwitz J.P, et al. 2014. Soil dust aerosols and

wind as predictors of seasonal meningitis incidence in Niger. Environmental health perspectives 122:679-686.

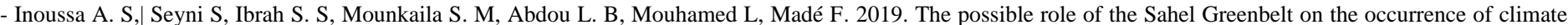
extremes over the West African Sahel. Atmos Sci Lett. 2019;20:e927.

- IPCC. 2013. Glossaire sur Changements climatiques, Suède. 79-202.

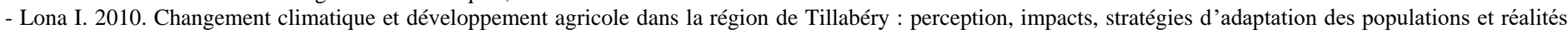
climatologiques dans la commune rurale de Diagourou, mémoire de DESS, FLSH, 75 p.

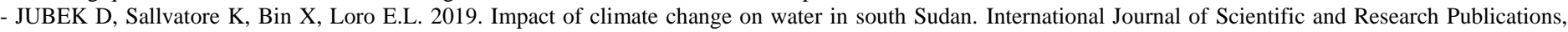
Volume 9, Issue 1, 112-126.

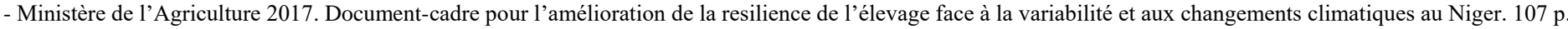

- OCHA. 2020. Bilan des inondations au 07 Septembre 2020 au Niger. Niamey, 3p.

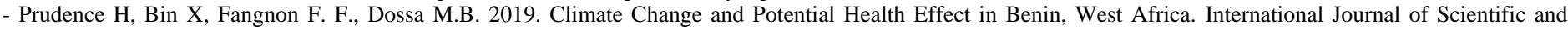
Research Publications, Volume 9, Issue 9, 625-633.

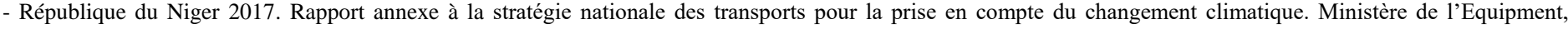
Ministère des Transports, $112 \mathrm{p}$.

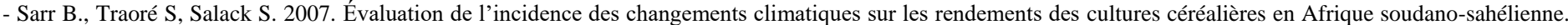
Centre Régional Agrhymet, CILSS, Niamey.

- YAYÉ H, DanguiOua A, Kadi H. 2010 : Évaluation de la vulnérabilité de l'agriculture aux changements climatiques dans le pays. Rapport, Niger, 42 p.

\section{AUTHOR}

Correspondence Author: Dr. Ali Nouhou, Department of Geography, FLSH, Abdou Moumouni University, Niamey, Niger. Email: nouhougeo@yahoo.de. Phone : +22795952323. Adress : BP 418, FLSH; UAM Niamey, Rep. du Niger 